\title{
SMEs: Peter Pan Syndrome or Firms not Grown Up? Creativity, Business Skills and Economic Growth of Danish Entrepreneurial Firms
}

\author{
By Mogens Dilling-Hansen ${ }^{*}$
}

According to several empirical studies, SMEs account for more than 50 per cent of all jobs in most OECD countries, with micro firms holding a significant share of the pie. The industry structure in Denmark is no exception and especially new entrepreneurial firms are considered as the foundation for future growth. SMEs have obvious reasons for focusing on economic growth, but particularly the very small entrepreneurial firms tend to maintain their status as micro firms. In this analysis, micro firm creativity is identified as a potential growth driver, and the subsequent empirical analysis tests whether it is an absence of internal or external resources that prevents micro firms from growing. The empirical analysis focuses on a sample of 36 micro firms and uses a longitudinal approach based on mixed methods to identify and evaluate the lack of internal resources, i.e. a basic business idea, a business plan, technical skills, leadership skills, marketing skills and internationalisation. Additionally, it is argued that, despite potential internal resource deficits, an important factor influencing the growth patterns of the creative firms analysed in the present study is their attitude towards lifestyle production.

Keywords: SME, micro firms, entrepreneurship, growth, creativity \& business skills

\section{Introduction}

Economic growth and employment are important for all types of countries as well as for individuals. Creating new jobs is the cornerstone in this process. Small and medium-sized firms (hereafter SMEs) are generally considered as the most important source of wealth creation because the majority of all new jobs are created in this type of firms. For instance, according to OECD (Mann, 2016), the fact that economic recovery is still lagging behind schedule after the financial crisis in 2008 could be attributed to SME performance being lower than expected (see for example BDO (2016)).

In a recent review of empirical evidence on SME job creation, Deijl, de Kok and Essen (2013) conclude that two major findings still hold. Firstly, more than $50 \%$ of all new jobs in the private sector are created in firms with no more than 100 employees. The dominant role of SMEs in job creation is found in both developed and developing countries. Secondly, the group of smaller firms is far from homogenous and the link between job creation and value creation/economic growth still needs to be analysed before the relative importance of smaller firms can be assessed. The question that remains unanswered, according to Deijl et al. (2013), is not whether SMEs create jobs

\footnotetext{
* Associate Professor, Aarhus University, Denmark.
} 
or not, but how important SMEs are in the creation of new jobs. It is clear that major changes in the relative significance of firm types are important to identify, but the focus of SME based analyses has gradually changed during the last decade. This change is mainly caused by two stylised facts: (i) the number of SMEs surviving is low compared to larger firms and (ii) micro firms are usually excluded from empirical analyses since they are not considered as 'real firms' having profit maximisation as their primary target. Additionally, they are frequently excluded from analysis due to the many non-measurable activities in which they engage.

The aggregate level of SME based job creation depends on a number of factors. Particularly, (a) the number of new firms, (b) the survival rate of the new firms and finally (c) the growth focus of new firms. The purpose of this paper is to analyse the external factors of economic growth, by investigating start-up survival rates and job creation over the last decade. The study also aims to contribute to understanding the internal factors of growth by analysing the value-added contribution of Danish micro firms. In this context, the basic objective of the study is to identify potential obstacles to growth, faced by micro and small companies. The starting point of the analysis of external factors is a general discussion of definitions used and global start-up rates of micro firms and SMEs, followed by a register based analysis of the survival rate of Danish start-up firms. The analysis of internal factors in Danish, creative micro firms is based on gaps between perceived and expected business skills. Finally, the effect of creativity is also analysed.

\section{Micro Firms and SMEs across Countries}

The difference between micro firms and SMEs chiefly lies in their relative sizes. The widely used European definitions of SMEs and micro firms are presented in table 1 below. The relative importance of each firm type with respect to level of employment is analysed cross-nationally in Kushnir (2006). The standard definition of these firm types, hereafter referred to as MSMEs, is usually based on a combination of the number of employed persons with a ceiling for turnover or financial balance. The majority of MSMEs are classified following the EU guidelines illustrated in table 1, while special attention should be paid to the definitions of micro firms, since this firm type is usually excluded from analyses for reasons related to the difficulty of defining their activities. However, when comparing firms over time and across nationalities, the European guidelines appear to be quite problematic. For instance, the typical upper limit of employment in MSMEs is 250 employees, while according to US definitions, firms with up to 500 employees could be also classified as MSMEs. Staff including the owners or not, periods not being directly comparable, sources of statistics being highly heterogeneous and missing data are some reasons for the discrepancy of the SME definition for international comparisons. 
Table 1. Definitions of Micro, Small and Medium-sized Firms, MSMEs

\begin{tabular}{|c|c|c|c|c|}
\hline \multirow[t]{2}{*}{ Enterprise category } & \multicolumn{4}{|c|}{ Ceilings } \\
\hline & $\begin{array}{l}\text { Staff Headcount } \\
\text { (number of persons } \\
\text { expressed in annual work } \\
\text { units) }\end{array}$ & Turnover & Or & Balance sheet total \\
\hline Medium-sized & $<250$ & $\leq € 50$ million & & $\leq € 43$ million \\
\hline Small & $<50$ & $\leq € 10$ million & & $\leq € 10$ million \\
\hline Micro & $<10$ & $\leq € 2$ million & & $\leq € 2$ million \\
\hline
\end{tabular}

Notes. Especially the definition of micro firms varies across nations (example Staff<5); see Kushnir et al. (2010). Source: European Commission (2003).

Lack of information, low validity of public data and lack of public interest are some obvious explanations of the very low focus on micro firms. Nevertheless, these firms do contribute significantly to the economy. Many of them have only one person employed, i.e. the owner is self-employed. Typically, personal, individual and creative services are key characteristics of the products produced by the micro firms.

The importance of small firms worldwide is evident from MSME Country Indicators from IFC/World Bank (Kushnir, 2006). As shown in table 2, since the distribution and relative significance may differ from developing to developed countries, the national statistics on MSMEs are divided into subgroups based on average national income. The grouping shown in table 2 illustrates the stylised fact that developing countries are lagging behind the industrialised countries with respect to income creation. "Low" income are the countries with annual GNI per capita below \$1,000. The "Upper middle" \& "High" groups have significantly higher earnings, but they are much more heterogeneous with respect to earnings. The "Upper middle" group of countries include countries with GNI per capita of around $\$ 3,000$ up to $\$ 12,000$ (including EU countries such as Bulgaria, Poland and Romania) and the "High" income group consists of industrialised countries with GNI per capita ranging from $\$ 13,000$ to more than $\$ 81,000$ per capita.

Evidently, the relative importance of MSMEs is high in developing countries and even higher in developed countries. The average employment share of 'non-financial business sectors' in EU28-countries is above 63\%, with the UK (54\%) being the only exception. The employment share of Danish MSMEs is equally high (65\%). Thus, if the relative importance of the SMEs is declining, as reported in Mann (2016) and BDO (2016), either external or internal factors must have a negative influence on job creation in MSMEs. Section 3 presents prior research on micro firms and their contribution to economic growth. Sections 4 and 5 analyse the development of the external and internal characteristics of the micro firms with a special focus on firm start-ups and the effect of creativity on the growth patterns of entrepreneurial firms. 
Vol. 3, No. $1 \quad$ Dilling-Hansen: SMEs: Peter Pan Syndrome or Firms not Grown Up?...

Table 2. Micro, Small and Medium-sized Firms' (MSMEs') Role in the Global Economy

\begin{tabular}{|c|c|c|c|c|c|}
\hline $\begin{array}{l}\text { Country type } \\
\text { (based on GNI/cap) }\end{array}$ & Low & $\begin{array}{l}\text { Lower } \\
\text { middle }\end{array}$ & $\begin{array}{l}\text { Upper } \\
\text { middle }\end{array}$ & High & $\begin{array}{c}\text { All } \\
\text { countries }\end{array}$ \\
\hline GNI, Average income per cap, US\$(a) & 511 & 2,299 & 6,772 & 33,659 & 13,361 \\
\hline Max income per cap, US\$(a) & 950 & 3,840 & 11,670 & 81,600 & 81,600 \\
\hline MSME employment share ${ }^{(a)}$ & 0.35 & 0.42 & 0.35 & 0.47 & 0.41 \\
\hline Share - micro of all MSME $E^{(a)}$ & 0.77 & 0.75 & 0.80 & 0.82 & 0.79 \\
\hline MSMEs per 1,000 people pa $^{(a)}$ & 16.9 & 27.7 & 28.2 & 41.6 & 30.6 \\
\hline Number of countries ${ }^{(a)}$ & 27 & 27 & 31 & 47 & 132 \\
\hline EU28 - employment share ${ }^{(b)}$ & - & - & - & - & 0.67 \\
\hline EU28 - value added share ${ }^{(b)}$ & - & - & - & - & 0.58 \\
\hline
\end{tabular}

Source: Based on background data from ${ }^{(a)}$ Kushnir et al.(2010) and ${ }^{(b)}$ European Commission (2015). Countries are divided into regions based on average income, GNI per cap, $n=132$. Countries are grouped using gross national income per capita to generate the four almost equally sized groups. Most of the data are from 2007/08, but especially low income countries report slightly older data. EU28 figures are expressed in the 2014 price level.

\section{Creativity and Economic Growth in Micro Firms and SMEs}

Creative SMEs are unique with respect to both their size and their creativity. Existing literature on this topic (see for example, Stein (1953), Kaufman and Sternberg (2007), Mumford (2011) and Runco and Jaeger (2012)) defines firms as being creative when their output is (i) new and innovative, (ii) of high quality and (iii) effective. All definitions regard firms in which the employees are doing creative work. Further, the resemblance to the standard understanding of innovation, as defined by the Oslo Manual, is striking; "a firm is creative when a new product or service is introduced in the market" (OECD, 2005).

On the other hand, the effect of being creative on SME growth is rather ambiguous. Economies of scale discussed below are expected to induce lower economic growth. However, several studies report empirical findings showing that small, young and creative firms potentially create increasing growth. As an example, Heunks (1998) finds that creativity in small firms increases growth and productivity, as these types of firms mainly benefit from innovation.

According to micro theory of industrial organisations, an industry structure generated by technically efficient firms is predicted to outperform inefficient firms. Performance differences will only prevail if firms differ in their factor endowments, financial structure etc. While the size distribution of firms undoubtedly depends on economies of scale, Leibenstein (1966) argues that lack of competition creates a monopolistic market structure. Then, lack of competition and firm inefficiency lead to welfare loss. In the present study, inefficiency is analysed on the individual firm level. It is argued that the general expectations regarding market structure and welfare loss do not differ for MSMEs. The overall level of economic growth generated from MSMEs is 
expected to depend on the effect of external factors. For instance, if the start-up development phase and survival rates are unaffected over time, the net growth contribution of the group of MSMEs is expected to be positive, particularly in the case of new and innovative entrepreneurial firms operating in developed countries.

Figure 1 presents Danish entrepreneurial activities over time. It appears that the number of new firms is positively correlated with overall, pro-cyclical economic activity. Additionally, it is shown that the relatively large decrease in activity during the financial crisis is now replaced by a slow process of economic recovery.

Figure 1. Number of New Firms in Denmark, 2001-13

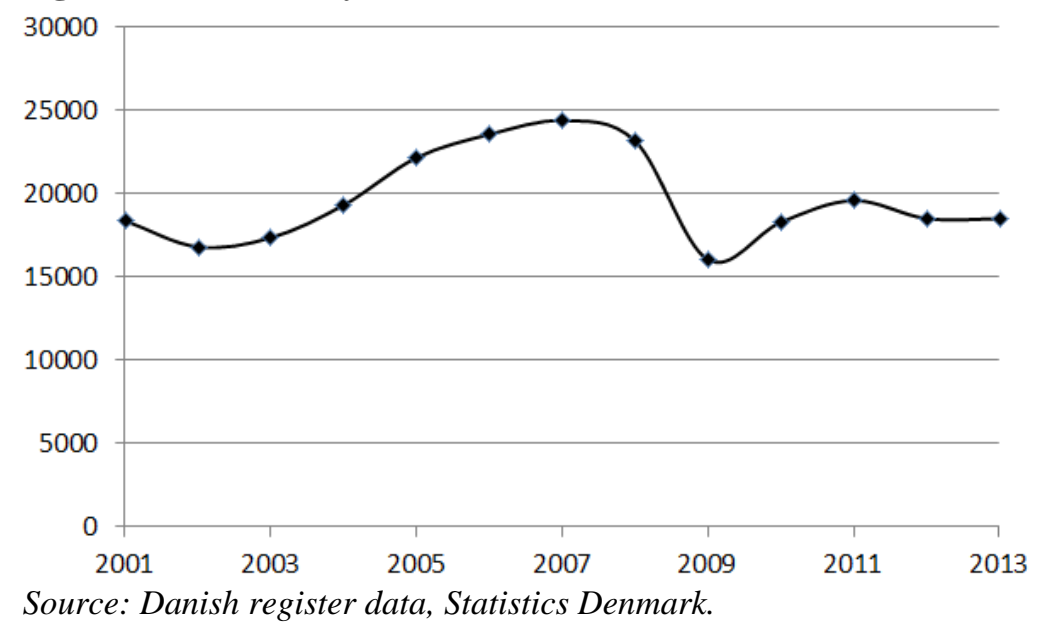

\section{Entrepreneurial Firm Survival}

The aggregate effect of external factors on value creation results in lower entrepreneurial activity and potential changes in firm survival. According to figure 1, a proportional effect of lower start-up rates is expected, but no unequivocal effect of changes in survival rates can be predicted. Standard micro economic arguments are based on differences in productivity between SMEs and larger firms, but it is not evident that recent changes in firm behaviour have created lower productivity and survival rates among SMEs. Differences in economies of scale are very likely to exist in all industries, but these are known before entering the market. Hence, mergers may dominate among SMEs and the probability of survival may also be higher among them. However, this may not have been the cause of the lower aggregate production during the period following the financial crisis, since all these trends were evident prior to the crisis.

Figure 2 illustrates the relation between age and survival rates of SMEs. In other words, the relationship between the firm start-up phase and firm survival among Danish firms is shown in figure 2. Data are drawn from new firms, based on the definition of by Statistics Denmark. A firm is characterised as being new in a given year, if a unique firm ID has been registered in this 
specific year; hence, the firm is not a technical spin-off of an existing conglomerate and the owners of the new firm are not serial entrepreneurs. Figure 1 shows the number of new firms in Denmark for the period 2001 to 2013 , indicating a clear pro-cyclical relation. The financial crisis starting in late 2008 has a clear and negative effect, as expected, and the level of new firms is still lagging behind that of the period before 2008. Considering that the Danish population is around 5.7 million, the numbers correspond to a start-up rate of $0.3-0.4 \%$ per capita. Although the financial crisis does have a negative effect on entrepreneurial activities, the overall level is not declining.

Figure 2. New Firms in Denmark: Absolute and Marginal Survival Rates in Denmark, 2001-13

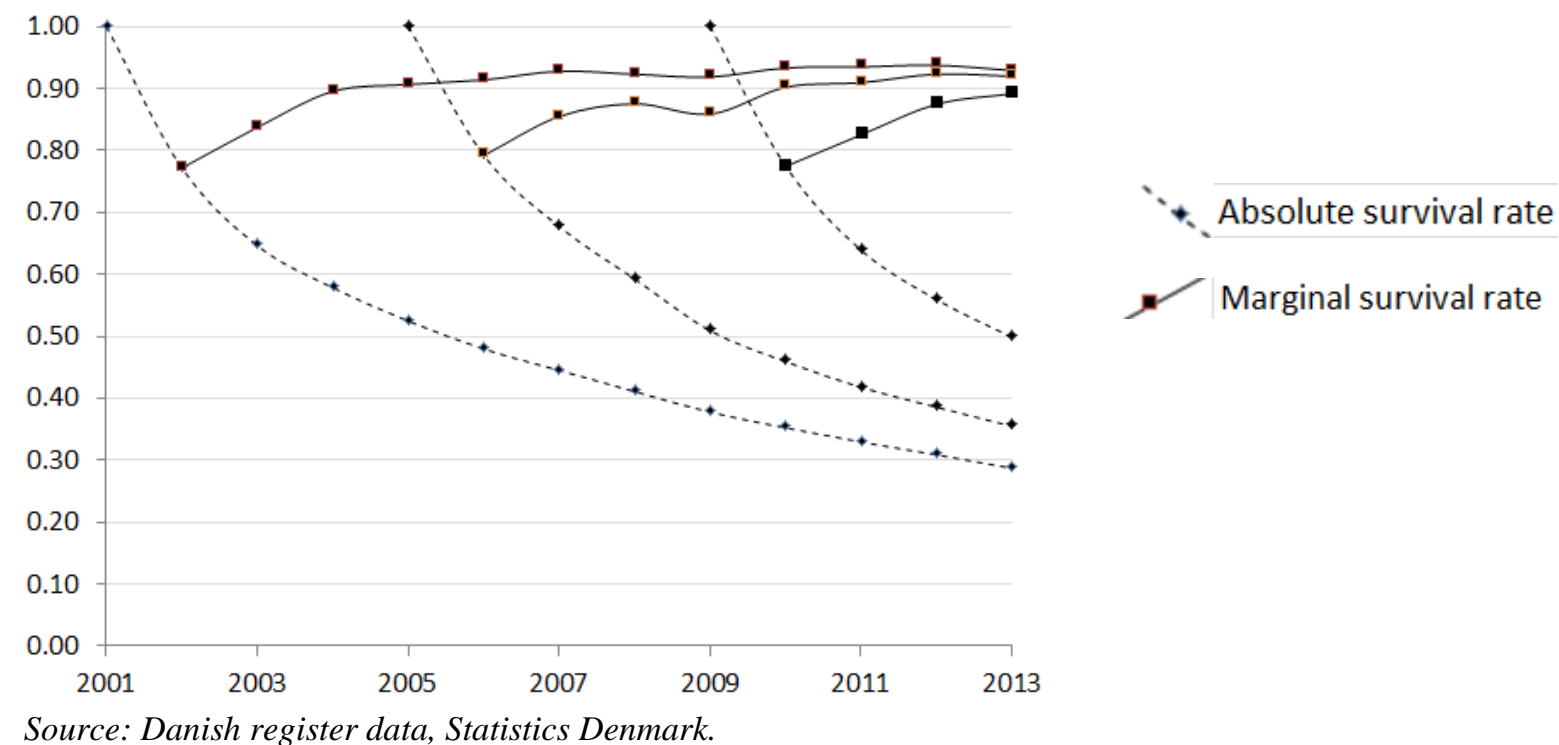

In this context, firm survival is defined as a firm managing to remain officially registered by public authorities in two consecutive periods. It is clear that this definition generates a positive bias on firm survival rates, since, in a legal sense, an active firm does not necessarily create added value. Survival rates of Danish firms are presented in figure 2, using the following definitions:

a. Absolute survival rate: Share of firms starting in period t that are still active in period $\mathbf{t}+\mathbf{i}$

b. Marginal survival rate: Share of firms in period t that are still active in period $\mathbf{t}+\mathbf{1}$

The absolute survival rate, showing how many firms, illustrated by three cohorts of new firms, are active after t periods, reveals a remarkably stable behaviour. In figure 2, the first cohort of new firms includes the firms starting in 2001. After 12 years (2013), only a share of $29 \%$ of the 2001 cohort of firms still remains active. The survival rate after 4 years is only marginally above $50 \%$, while the firms starting in 2005 and 2009 experience similar survival rates. 
The marginal survival rate illustrates how the probability of survival changes over time. The large decline in absolute survival rate is caused by low marginal survival rates when firms were young. For instance, in 2001 the marginal survival rate was $77 \%$ and equal to the absolute survival rate. Following the 2001 cohort in 2002 and 2003, the number of surviving firms is calculated, conditional on the firms having survived the first year. In this way, the expected higher marginal survival rate is estimated. The marginal survival rate of the 2001 cohort increases from $77 \%$ to $90 \%$ in three years and the longrun marginal survival rate varies from $92 \%$ to $94 \%$. The survival rates for each period are statistically equal and only firms starting a few years prior to the crisis systematically deviate from this pattern. Even though an expected drop is evident in 2009, the absolute survival rate, however, fully recovers in a year.

Three important conclusions can be drawn from figures 1 and 2. The first conclusion is that the overall entrepreneurial activity is affected pro-cyclically by external factors and no negative trend is found after the financial crisis. The second conclusion is that new firms are very volatile with respect to survival and only $50 \%$ of all starting firms can expect to exist after 4 years. Especially the first three years of operating are problematic, but after passing this threshold, the probability of survival stabilises at around $90 \%$. Finally, the third conclusion is that despite changes in start-up rates occurring over time, the survival structure of new firms has been remarkably stable over the last decade. The absolute and marginal survival rates slightly decreased in the first year after the financial crisis (2009), but otherwise the absolute and marginal survival rates did not change. It is common that a new firm faces very tough obstacles during its first three years of existence, but after that period, its survival rate is very much like that of all other firms. Industries are in general volatile, and one consequence of this is that around $10 \%$ of all firms disappear every year.

\section{MSMEs Growth: Peter Pan Syndrome?}

The external factors analysed in the previous section, such as the start-up development phase and survival rates, cannot fully explain why MSMEs do not grow as expected. It is true that slightly fewer firm start-ups are found after the financial crisis, but the drop was expected and the overall survival rate of new firms seems remarkably stable over the last decade. The conclusion is that it may be the internal factors that create lower growth. In order to understand why MSMEs apparently face larger problems, the underlying factors generating economic growth must be identified.

MSMEs could potentially be less efficient in general. In a neoclassical context, inefficiency means that profit maximisation does not take place. Specifically, Leibenstein (1966) argues that for various reasons the cost function gradually moves away from the optimum borderline. Based on a thorough literature review, Leibenstein (1966) highlights three basic reasons: (i) incomplete contracts between firm and workers, (ii) "incomplete" 
production functions and (iii) asymmetric information about the markets. The basic arguments for firms becoming gradually sloppier about cost structure are apparently found in psychology: lack of incentives, micro and macro conditions etc. Without going into details about the relative importance of these factors, the analysis of the poor firm performance is limited to a discussion about general welfare losses due to lack of innovation. Future growth is expected to decline as a consequence of poor efficiency in MSMEs, but the major problem with these arguments is that the theory does not support that especially MSMEs are less efficient.

Another problem for MSMEs is the stylised fact that they do not fully exploit economies of scale, thus operating at lower productivity levels. This argument is valid, but no hard evidence is found supporting the claim that MSME productivity has gone down compared to that of larger firms during the last decade. The lack of theoretical support for declining growth in MSMEs means that predictors of poor performance should be identified within the firms. Based on data provided by the World Bank, the problem is more prevalent in developed countries. Kushnir et al. (2010) used the World Bank Enterprise Survey conducted in 98 countries to identify $15 \mathrm{key}$ obstacles to business in developing countries: access to finance; access to land; business licensing and permits; corruption; courts; crime, theft and disorder; customs and trade regulations; electricity; inadequately educated workforce; labour regulations; political instability; practices of competitors in the informal sector; tax administration; tax rates and transport. Among these, access to finance, corruption, electricity, political instability, practices of competitors in the informal sector and tax rates are considered to be the most important. Expected effects on productivity are found for some of these factors. For instance, the provision of basic services in developing countries, such as electricity, and access to finance in smaller firms are important determinants of productivity and growth. However, these conditions have not changed fundamentally during the last years.

Hence, potential factors leading to lower growth rates could be internal. One factor of special interest for micro firms is the Peter Pan Syndrome, used to describe the recent empirical finding of declining growth rates among micro firms. Here, the relevant question to address is why these firms do not grow as much as the framework conditions actually predict?

A recent Danish survey focuses on the low growth rates evident among MSMEs (BDO, 2016). It is argued that MSMEs' low growth rates can chiefly be attributed to biased economic incentives of their owners. As long as the competition in the markets is hard and the basic earnings of the firm are low, the firm focuses on efficiency, but when these external threats become less problematic, the growth within the firm almost disappears. This effect is also defined as the "BMW syndrome", meaning that when the owner of a firm can afford basic luxury goods, profit maximisation becomes less important. Several arguments for the importance of this effect are rooted in the X-efficiency theory (Leibenstein, 1966). The main argument is that profit maximisation is only one of several motives for micro firms. In Dilling-Hansen et al. (2011), 
these firm types are defined as lifestyle firms, which means that the basic motive for starting a firm is not profit maximisation but the creation of revenue to support basic costs of living.

\section{Research Design for Analysing Small Creative Firms}

As discussed before, the purpose of the present study is to identify obstacles to growth in small creative micro firms. It is shown that global economic conditions as well as general framework conditions for entrepreneurial activities may still have an important influence on start-up rates and firm survival. However, firms in developed countries do not face these problems to the same extent as previously. No major changes in framework conditions have been identified during the last decade, so the explanation of declining growth should be explored within the firm.

The micro firms studied here are self-declared creative firms. Creative firms are very dedicated to their business, considering creativity as their core competence, while their owners understand that basic economic skills are needed in order to develop the firm. The firms are analysed in a window of three years, starting in the 2016. Qualitative research is used to identify the obstacles to future growth, aspiring to assist firms to achieve future growth. Subsequently, quantitative analysis is conducted, based on self-reported statements about the firms' current status to identify each firm's ideal position. Individual preferences are measured on a Likert scale and the model developed for the analysis is inspired by the service quality literature.

Ordinally scaled statements are used to measure preferences, using differences between expected and perceived values. The model identifies a gap between expected and perceived values on a specific dimension, and if a positive gap is found on the dimension, perceived values are expected to change in order to minimise this gap (Zeithaml, Parasuraman and Berry (1990)). The model developed to identify obstacles to future growth in small and creative firms follows the below steps in collecting information from the firms:

Step 1: Screening of 40 self-declared creative SMEs located in Denmark and Sweden (districts close to Copenhagen, Denmark)

Identification of obstacles which affect future growth Qualitative research (depth interviews and secondary data)

Step 2: Assessment of the relative importance of the growth dimensions Quantitative research (survey based self-reporting)

Step 3: Assessment of the identified growth dimensions: perceived and expected position

Quantitative research (survey based self-reporting)

The 40 firms included in the study sample are selected among micro firms which declared their focus on creativity. New and mature ( $>3$ years old) firms are equally represented in the sample. 
Factors Influencing the Future Economic Growth of MSMEs

Based on the qualitative research, a number of internal and external dimensions affecting future economic growth are identified:

i. Creativity, innovation, development (internal)

ii. Managerial economics (cost focus) (internal)

iii. Firm management (internal)

iv. Customer brand perception (market-external)

v. Quality of the product (market-external)

vi. Sales and networking (market-external)

The identification of the six dimensions has two purposes. Firstly, the dimensions are used in the gap analysis below to determine potential obstacles to growth. Secondly, they are used to design the content of future interventions designed to help firms to improve performance.

A few descriptive characteristics of the firms in the sample can be seen in table 3, revealing a number of interesting observations. Firstly, the firms are indeed micro firms and they are also quite young. Secondly, average annual firm sales are low; specifically, too low to pay a standard salary to the owner of the firm, given that the average Dane has an income of 299,000 DKK, according to Statistics Denmark (2016). Thirdly, all firms are very focused on growth, but only growth within the framework of a micro firm. Finally, the expected average sales level per employee is very much in line with average sales per employee in private industries.

Table 3. Descriptive Statistics of the Sample of Creative Micro Firms

\begin{tabular}{lccc}
\hline & $\begin{array}{c}\text { Danish } \\
\text { firms }\end{array}$ & $\begin{array}{c}\text { Swedish } \\
\text { firms }\end{array}$ & $\begin{array}{c}\text { All } \\
\text { firms }\end{array}$ \\
\hline Number of firms & 20 & 16 & 36 \\
\hline Age of firms & 1.5 & 1.5 & 1.5 \\
\hline Staff & 0.5 & 0.4 & 0.4 \\
\hline Staff expansion (expected) & 2.3 & 1.6 & 2,0 \\
\hline Sales (1,000 KR) & 158 & 134 & 149 \\
\hline Sales (expected 1,000 KR) & 1,659 & 793 & 1,324 \\
\hline
\end{tabular}

Source: Nordic Buzz Survey, 2016

\section{Gap Analysis of Small Creative Firms}

The relative importance and the gaps in the six obstacles to growth are calculated and the results are shown in the following tables. Table 4 presents the perceived importance of the six dimensions for Danish and Swedish firms. The reported weights are very high for creativity (internal factor) and brand and quality (market factors). The "core business economics" dimensions are downscaled in importance, and it is interesting to observe some cultural differences. For instance, Danish firms are more concerned about costs while Swedish firms are more concerned about management. 
Table 4. Relative Importance of Factors Creating Firm Growth

\begin{tabular}{lccc}
\hline & $\begin{array}{c}\text { Danish } \\
\text { firms }\end{array}$ & $\begin{array}{c}\text { Swedish } \\
\text { firms }\end{array}$ & $\begin{array}{c}\text { All } \\
\text { firms }\end{array}$ \\
\hline Creativity, innovation, development & 9.4 & 9.6 & 9.5 \\
\hline Managerial economics (cost focus) & 8.3 & 7.0 & 7.7 \\
\hline Firm management & 6.1 & 7.3 & 6.6 \\
\hline Customer brand perception & 9.4 & 9.4 & 9.4 \\
\hline Quality of the product & 9.6 & 9.3 & 9.4 \\
\hline Sales and networking & 7.2 & 7.5 & 7.3
\end{tabular}

Source: Nordic Buzz Survey, 2016. Averages are based on answers on a 1-10 scale.

Finally, it is interesting to note that marketing efforts (market access, ecommerce, networking with customers) are not considered as important factors for future growth among the Danish and Swedish firms included in the sample.

Table 5. Gaps between Perceived and Expected Positions

\begin{tabular}{|c|c|c|c|}
\hline & $\begin{array}{l}\text { Perceived } \\
\text { value }\end{array}$ & $\begin{array}{l}\text { Expected } \\
\text { value }\end{array}$ & $\begin{array}{c}\text { Gap/ } \\
\text { (t-value) }\end{array}$ \\
\hline Creativity, innovation, development & 5.2 & 6.7 & $1.5 /(8.3)$ \\
\hline Managerial economics (cost focus) & 4.4 & 5.6 & $1.2 /(5.7)$ \\
\hline Firm management & 5.1 & 6.5 & $1.4 /(9.3)$ \\
\hline Customer brand perception & 5.0 & 6.7 & $1.7 /(9.6)$ \\
\hline Quality of the product & 4.7 & 5.7 & $1.0 /(6.7)$ \\
\hline Sales and networking & 4.4 & 6.4 & $1.9 /(11.6)$ \\
\hline \multicolumn{4}{|c|}{$\begin{array}{l}\text { Source: Nordic Buzz. Survey, 2016. A gap exists if the expected value is larger than the } \\
\text { perceived value. Averages are based on answers to Likert scaled questions (1-7). The reported } \\
\text { t-values in brackets are significant (rejecting } H_{0} \text { of no positive gap) for values above 1.7: Any } \\
\text { gap higher than } 0.3 \text { is statistically significant }(\alpha=5 \%) \text {. }\end{array}$} \\
\hline
\end{tabular}

Interpretation of the gaps shown in table 5 is based on understanding the perceived values of the firms. These perceptions are information measured on an ordinal scale; the relatively high value $(>4)$ on all dimensions indicates that the small creative firms actually do find their current position acceptable. This is one of the shortcomings of self-reported performance, and therefore the relevant focus must be on the gaps between perceived and expected values reported in the last column of table 5.

The gaps presented in table 5 are all positive, statistically significant and high on all dimensions, using a 1-7 Likert scale. Thus, it is considered equally important to focus on activities improving the firm's position on all six dimensions and to enhance the creative dimension in the future in order to generate higher future growth.

Creative micro firms are very dedicated and ambitious as long as they can maintain their focus on creativity; this is evident from the high weight placed on creativity in table 4. Taken together, this finding and the observation that future firm development should be in balance with a firm's creativity illustrate the link between growth and focus on creativity. Despite all firms already investing heavily in creativity, the latter is the most important gap to minimise, together with brand perception and market access. At the same time, expected 
growth in sales does not necessarily match standard economic goals, suggesting that firm growth will not take place as expected.

In line with the findings presented in table 5, Leibenstein's (1966) arguments of X-efficiency are not validated by the present qualitative research. Strong commitment to the creative process is the prevailing trend concerning future development. On the other hand, the Peter Pan syndrome hypothesis cannot be rejected. The strong belief in the future development and growth is accompanied by aspirations for future earnings, being lower than what an average Dane is earning. Undoubtedly, future growth and earnings, falling below a sustainable level of value creation do not match with profit maximisation and firm growth.

\section{Conclusions}

The relative importance of micro, small and medium-sized firms for economic prosperity is evidently high. The recent debate on the current low rates of economic growth indicates that slow growth could be attributed to poorly performing small and micro firms. The present analysis shows that changes in entrepreneurial activities and lower survival rates of MSMEs alone cannot explain lower economic growth. Additionally, it is found that internal firm factors influence growth. For instance, one potential problem with smaller privately owned firms may be that the owners' focus is not entirely on profit maximisation. Lack of incentives to grow after a certain threshold is reached cannot be rejected as an explanation of the low growth rate of MSMEs, and the findings of this paper suggest that the potential problem may especially arise from micro firms.

The creative micro firms participating in this project appear to be very dedicated; they are focused on creativity and they all want to improve their performance. Internal factors, such as management and cost focus, and market factors, such as brand value, quality and marketing, appear to be key factors in this process. However, the basic conclusion reached by this study is that creativity is the single most important key characteristic of the firm and growth is only relevant as long as creativity can be maintained. To summarise, it could be argued that lifestyle behaviour for these creative micro firms could be even more important than economic growth. 


\section{References}

BDO. (2016) SMV Barometret (in Danish). København: BDO Statsautoriseret revisionsaktieselskab,. Available at: www.bdo.dk/smvbarometret)

Deijl C, de Kok J, and Essen VV (2013) Is small still beautiful? Literature review of recent empirical evidence on the contribution of SMEs to employment creation. Deutsche Gesellschaft für Internationale Zusammenarbeit (GIZ) GmbH.

Dilling-Hansen, M. \& S. Jensen (2011), Lifestyle production: Transformation from manufacturing to knowledge based production using innovation, International Journal of Economic Sciences and Applied Research 4 (1): 35-54.

European Commission. (2003) Commission Recommendation of 6 May 2003 concerning the definition of micro, small and medium-sized enterprises. Brussels: European Commission. Available at: https://web.archive.org/web/201503060717 17/http://ec.europa.eu/enterprise/policies/sme/files/sme_definition/sme_report_2 009_en.pdf

European Commission. (2015) Annual Report on European SMEs 2014 / 2015SMEs start hiring again. SME PERFORMANCE REVIEW 2014/2015. Brussels: Directorate-General for Internal Market, Industry, Entrepreneurship and SMEs.

Heunks FJ (1998) Innovation, Creativity and Success, Small Business Economics, 10(3): 263-272, 1998.

Kaufman JC, Sternberg RJ (2007) Resource review: creativity. Change, 39(4): 55-58.

Kushnir, K (2006) How do economies define micro, small and medium enterprises (MSMEs). Companion Note for the MSME Country Indicators.

Kushnir K, Mirmulstein ML, and Ramalho R (2010) Micro, Small, and Medium Enterprises around the World: How Many Are There, and What Affects the Count? Washington, DC: World Bank and International Finance Corporation (IFC).

Leibenstein H (1966) Allocative efficiency vs." X-efficiency". The American Economic Review, 56(3): 392-415.

Mann CL (2016) Policymakers: Act now to break out of the low-growth trap and deliver on our promises. OECD. Available at: https://oecdecoscope.wordpress.com/2016/06/01/policymakers-act-now-to-break-out-of-the-low-growth-trap-anddeliver-on-our-promises/

Mumford,MD (2003) Where Have We Been, Where Are We Going? Taking Stock in Creative Research, Creative Research Journal 15: 107-120.

OECD. (2005) Oslo Manual: Guidelines for Collecting and Interpreting Innovation Data, 3rd Edition, OECD 2005. Available at: http://www.oecd.org/sti/oslomanual

Runco MA, Jaeger GJ (2012) The Standard Definition of Creativity. Creative Research Journal 24: 92-96.

Stein MI (1953) Creativity and Culture. The Journal of Psychology 36: 311-322.

Statistics Denmark. (2016) The Average Dane. Available at: https://www.dst.dk/da/ Statistik/emner/gennemsnitsdanskeren

Zeithaml V, Parasuraman A and. Berry LL (1990) Delivering Quality Service. Balancing Customer Perceptions and Expectations. New York: Simon and Schuster. 
